\title{
The impact of plasma triglyceride and apolipoproteins concentrations on high-density lipoprotein subclasses distribution
}

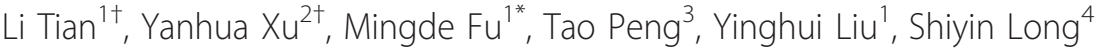

\begin{abstract}
Objective: To investigate the effect of triglyceride (TG) integrates with plasma major components of apolipoproteins in HDL subclasses distribution and further elicited the TG-apolipoproteins (apos) interaction in the processes of high density lipoprotein (HDL) mature metabolic and atherosclerosis related diseases.

Methods: Contents of plasma HDL subclasses were quantities by two-dimensional gel electrophoresis associated with immunodetection in 500 Chinese subjects.

Results: Contents of pre $\beta_{1}-H D L, H D L_{3 a}$, and apoB-100 level along with apoB-100/A-I ratio were significantly increased, whereas there was a significant reduction in the contents of $\mathrm{HDL}_{2}$, apoA-I level as well as apoC-III/C-II ratio with increased TG concentration. Moreover, pre $\beta_{1}-\mathrm{HDL}$ contents is elevated about $9 \mathrm{mg} / \mathrm{L}$ and $\mathrm{HDL}_{2 \mathrm{~b}}$ contents can be reduced $21 \mathrm{mg} / \mathrm{L}$ for $0.5 \mathrm{mmol} / \mathrm{L}$ increment in TG concentration. Moreover, with increase of apoAI levels, $\mathrm{HDL}_{2 b}$ contents were marginally elevated in any TG concentration group. Furthermore, despite of in the apoB-100/A-I $<0.9$ group, the contents of pre $\beta_{1}-\mathrm{HDL}$ increased, and those of $\mathrm{HDL}_{2 \mathrm{~b}}$ decreased significantly for subjects in both high and very high TG levels compared to that in normal TG levels. Similarly, in the apoB-100/ A-I $\geq 0.9$ group, the distribution of HDL subclasses also showed abnormality for subjects with normal TG levels.

Conclusions: The particle size of HDL subclasses tend to small with TG levels increased which indicated that HDL maturation might be impeded and efficiency of reverse cholesterol transport(RCT) might be weakened. These data suggest that TG levels were not only significantly associated with but liner with the contents of pre $\beta_{1}-\mathrm{HDL}$ and $\mathrm{HDL}_{2 \mathrm{~b}}$. They also raise the possibility that the TG levels effect on $\mathrm{HDL}$ maturation metabolism are subjected to plasma apolipoproteins and apolipoproteins ratios.
\end{abstract}

\section{Background}

Several studies were published in the 1970s reporting an inverse association between plasma high density lipoprotein cholesterol (HDL-C) level and coronary heart disease (CHD) [1], confirmed since then by numerous additional studies throughout the world. HDL-C was first endorsed as a formal independent risk factor for CHD in the 1980s and has since evolved into one of the few "traditional" risk factors used by clinicians to assess cardiovascular risk. Because of the association of low HDL-C with other atherogenic factors, a low HDL-C is not as strongly

\footnotetext{
* Correspondence: Apolipoprotein2009@yahoo.com.cn

† Contributed equally

'Laboratory of Endocrinology and Metabolism, West China Hospital, Sichuan University, Chengdu 610041, Sichuan, People's Republic of China

Full list of author information is available at the end of the article
}

independent in its prediction of CHD as suggested by usual multivariate analysis [2]. Subjects with low HDL-C display marked changes in their HDL composition and subclass distribution. Some studies indicate that larger $\mathrm{HDL}_{2}$ particles as well as HDL mean particle size are reduced in subjects with low HDL-C [3-7]. Case-control studies indicate that the inverse relation between HDL-C levels and CHD is accounted for by the largest HDL particles, the $\mathrm{HDL}_{2 \mathrm{~b}}$ subclass [8]. In addition, familial low-HDL-C subjects exhibit higher levels of inflammation markers such as high-sensitivity $\mathrm{C}$-reactive protein (hsCRP) [9].

HDL metabolism is somewhat more complex than that of the other major lipoprotein fractions. It is well known that HDL does not represent a sum of identical particles but is rather comprised of discrete subclasses that differ

\section{C) Biomed Central}


related to charge, density, size, composition, shape and physiological functions [10]. Using two-dimensional gel electrophoresis coupled with immunoblotting, HDL can be divided into large, cholesterol-rich $\left(\mathrm{HDL}_{2 \mathrm{a}}\right.$ and $\mathrm{HDL}_{2 \mathrm{~b}}$ ), small-sized $\left(\mathrm{HDL}_{3 \mathrm{c}}, \mathrm{HDL}_{3 \mathrm{~b}}, \mathrm{HDL}_{3 \mathrm{a}}\right.$, and pre $\beta_{1^{-}}$ HDL) and pre $\beta_{2}$-HDL $[11,12]$. Epidemiological studies have shown that individual HDL subclasses are not equally atheroprotective [13], a decrease content of the large-sized $\mathrm{HDL}_{2 b}$ particles and an increase content of the small-sized pre $\beta_{1}$-HDL particles were highly and significantly associated with the risk of CHD $[14,15]$.

Our laboratory had investigated the effect of plasma triglyceride (TG) and total cholesterol (TC) on the distribution of the HDL subclasses. The findings demonstrated that plasma increased TG and TC concentrations cause the particles size of HDL subclasses tend to smaller, creating an environment of diminished reverse cholesterol reverse cholesterol transport(RCT)[12,16-18]. The elevated TG levels are usually not only accompanied by other lipid metabolic disturbance but also associated with the change in plasma apolipoprotein levels. The TG and other lipids have been extensively studied for their effect on HDL subclasses distribution. Less information is known regarding the impact of TG combine with plasma apolipoproteins on profile of HDL subclasses distribution.

In this study, we mainly focused on the effect of TG integrate with plasma major components of apolipoproteins in
HDL subclasses contents distribution and further elicited the TG-apolipoproteins interaction in the processes of HDL mature metabolism.

\section{Results}

Concentrations of plasma lipids, apolipoproteins, and ratios of lipids and apolipoproteins among subjects classified by levels of TG

Table 1 showed that in the population, the concentration of TG was $2.1 \pm 0.3 \mathrm{mmol} / \mathrm{L}$ which exceeds normal TG levels recommended in the ATP-III of NCEP guidelines that indicated a substantial proportion of subjects with hypertriglyceridemia (HTG). Moreover, the body mass index(BMI) was increased with the elevation of the TG levels and the subjects in borderline-high, high and very high TG groups were characterized by an adverse lipid profile which comprised of increased concentrations of TG, TC, low density lipoprotein cholesterol(LDL-C) and levels of apoB-100, apoC-II, and apoC-III along with the ratios of TG/HDL-C, TC/HDL-C,LDL-C/HDL-C, and apoB-100/A-I; however, lower levels of HDL-C, apoA-I and apoC-III/C-II ratio compared with normal TG subjects.

\section{The apoA-I contents of HDL subclasses among subjects} categorized based on levels of TG

Characteristics of the HDL subclass contents distribution profile were displayed in Table 2. The contents of small-

Table 1 Concentrations of plasma lipids, apolipoproteins, and ratios of lipids, and apolipoproteins among subjects categorized by TG levels

\begin{tabular}{|c|c|c|c|c|c|}
\hline & $\begin{array}{c}\text { Total } \\
(n=500)\end{array}$ & $\begin{array}{l}\text { Normal TG } \\
(n=202)\end{array}$ & $\begin{array}{l}\text { Borderline-high TG } \\
\qquad(\mathrm{n}=77)\end{array}$ & $\begin{array}{l}\text { High TG } \\
(n=183)\end{array}$ & $\begin{array}{l}\text { Very high TG } \\
\quad(n=38)\end{array}$ \\
\hline Age(yr) & $56.7 \pm 9.0$ & $55.6 \pm 9.7$ & $55.8 \pm 8.7$ & $57.3 \pm 9.2$ & $58.6 \pm 9.0$ \\
\hline Female/male & $175 / 325$ & $72 / 130$ & $26 / 51$ & $64 / 119$ & $13 / 25$ \\
\hline Sex ratio(\%) & 53.8 & 55.4 & 50.9 & 53.8 & 52.0 \\
\hline $\mathrm{BMI}\left(\mathrm{kg} / \mathrm{m}^{2}\right)$ & $23.4 \pm 2.2$ & $22.4 \pm 2.5$ & $23.4 \pm 2.8$ & $24.5 \pm 2.8^{a \S}$ & $26.2 \pm 3.0^{a \S b \S}$ \\
\hline $\mathrm{TG}(\mathrm{mmol} / \mathrm{L})$ & $2.1 \pm 0.3$ & $1.0 \pm 0.2$ & $1.9 \pm 0.2^{a \S}$ & $3.3 \pm 0.8^{\mathrm{a} \S \mathrm{b} \S}$ & $7.1 \pm 1.0^{a \S b \S c \S}$ \\
\hline $\mathrm{TC}(\mathrm{mmol} / \mathrm{L})$ & $5.4 \pm 0.9$ & $5.0 \pm 0.8$ & $5.2 \pm 0.9$ & $5.5 \pm 0.9^{a \neq}$ & $6.1 \pm 0.8^{a \S b \S c \neq}$ \\
\hline LDL-C(mmol/L) & $3.3 \pm 0.4$ & $2.8 \pm 0.7$ & $3.0 \pm 0.8$ & $3.4 \pm 0.8^{\mathrm{a} \neq \mathrm{b}^{*}}$ & $3.5 \pm 0.9^{\mathrm{a} \neq \mathrm{b} \neq}$ \\
\hline $\mathrm{HDL}-\mathrm{C}(\mathrm{mmol} / \mathrm{L})$ & $1.2 \pm 0.3$ & $1.6 \pm 0.3$ & $1.3 \pm 0.4^{\mathrm{a} \S}$ & $1.0 \pm 0.4^{\mathrm{a} s b \S}$ & $0.9 \pm 0.2^{a \S b \S}$ \\
\hline ApoA-I(mg/L) & $1270.2 \pm 102.5$ & $1319.1 \pm 193.8$ & $1300.0 \pm 178.4$ & $1257.2 \pm 151.2$ & $1187.9 \pm 123.2^{a \neq b \neq c^{*}}$ \\
\hline ApoB-100(mg/L) & $905.6 \pm 98.4$ & $804.3 \pm 97.7$ & $905.6 \pm 108.4^{a \neq}$ & $1015.4 \pm 119.1^{a \S b \neq}$ & $1167.2 \pm 113.9^{a \S b \S c \neq}$ \\
\hline ApoC-II(mg/L) & $62.5 \pm 10.8$ & $45.4 \pm 9.5$ & $66.7 \pm 11.9^{a^{*}}$ & $101.9 \pm 17.3^{a \S b \neq}$ & $140.2 \pm 25.3^{a \S b \S c \neq}$ \\
\hline ApoC-III(mg/L) & $150.2 \pm 25.6$ & $112.9 \pm 21.9$ & $152.3 \pm 23.2^{a \S}$ & $196.8 \pm 27.5^{a \S b \S}$ & $252.4 \pm 29.8^{a \S b \S c \S}$ \\
\hline TG/HDL-C & $2.1 \pm 0.2$ & $0.8 \pm 0.2$ & $1.3 \pm 0.3^{a \S}$ & $3.5 \pm 0.9^{\mathrm{a} s \mathrm{~b} \varsigma}$ & $5.4 \pm 0.9^{a \S b \S c \S}$ \\
\hline TC/HDL-C & $4.8 \pm 0.3$ & $4.0 \pm 1.0$ & $4.7 \pm 1.0^{\mathrm{a}^{*}}$ & $5.7 \pm 1.0^{\mathrm{a} \S \mathrm{b} \neq}$ & $6.1 \pm 1.1^{a \S b \S}$ \\
\hline LDL-C/HDL-C & $2.8 \pm 0.2$ & $1.3 \pm 0.2$ & $1.8 \pm 0.3^{a \neq}$ & $2.6 \pm 0.5^{a \xi b \neq}$ & $3.0 \pm 0.9^{a \S b \S c^{*}}$ \\
\hline ApoB-100/A-I & $0.7 \pm 0.2$ & $0.4 \pm 0.1$ & $0.5 \pm 0.2$ & $0.8 \pm 0.2^{\mathrm{a} b \mathrm{~b} \neq}$ & $1.1 \pm 0.3^{a \S b \S c \neq}$ \\
\hline ApoC-III/C-II & $2.4 \pm 0.3$ & $2.5 \pm 0.3$ & $2.3 \pm 0.2$ & $1.9 \pm 0.2^{\mathrm{a} \S \mathrm{b} \neq}$ & $1.8 \pm 0.2^{a \xi b \neq}$ \\
\hline
\end{tabular}

Values are expressed as Mean \pm S.D.

${ }^{*} P<0.05,{ }^{\ddagger} P<0.01,{ }^{\S} P<0.001$.

${ }^{\text {a }}$ Significantly different from Normal TG group.

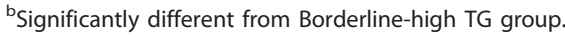

'Significantly different from High TG group. 
Table 2 The apoA-I contents of HDL subclasses among subjects categorized by TG levels

\begin{tabular}{|c|c|c|c|c|}
\hline & $\begin{array}{l}\text { Normal TG } \\
(n=202)\end{array}$ & $\begin{array}{l}\text { Borderline-high TG } \\
\quad(\mathrm{n}=77)\end{array}$ & $\begin{array}{l}\text { High TG } \\
(n=183)\end{array}$ & $\begin{array}{c}\text { Very high TG } \\
(\mathrm{n}=38)\end{array}$ \\
\hline$\overline{\operatorname{Pre} \beta_{1}-\mathrm{HDL}(\mathrm{mg} / \mathrm{L})}$ & $80.6 \pm 11.4$ & $104.9 \pm 17.8 \mathrm{a}^{*}$ & $129.5 \pm 21.9^{\mathrm{a} \& \mathrm{~b} \neq}$ & $153.0 \pm 27.8^{a \& b \neq c^{*}}$ \\
\hline Pre $\beta_{2}-\mathrm{HDL}(\mathrm{mg} / \mathrm{L})$ & $51.6 \pm 8.6$ & $58.9 \pm 7.9$ & $61.4 \pm 8.7$ & $64.9 \pm 9.0$ \\
\hline $\mathrm{HDL}_{3 \mathrm{c}}(\mathrm{mg} / \mathrm{L})$ & $68.8 \pm 9.2$ & $71.4 \pm 9.6$ & $74.3 \pm 9.0$ & $75.8 \pm 9.0$ \\
\hline $\mathrm{HDL}_{3 \mathrm{~b}}(\mathrm{mg} / \mathrm{L})$ & $138.7 \pm 20.7$ & $143.7 \pm 23.6$ & $148.4 \pm 21.9$ & $151.4 \pm 27.0$ \\
\hline $\mathrm{HDL}_{3 \mathrm{a}}(\mathrm{mg} / \mathrm{L})$ & $238.7 \pm 30.6$ & $285.5 \pm 28.7^{\mathrm{a} \neq}$ & $310.9 \pm 31.7^{\mathrm{a} s b^{*}}$ & $384.2 \pm 40.1^{\text {asbscs }}$ \\
\hline $\mathrm{HDL}_{2 \mathrm{a}}(\mathrm{mg} / \mathrm{L})$ & $292.7 \pm 27.5$ & $267.9 \pm 24.1^{\mathrm{a}^{*}}$ & $227.5 \pm 29.6^{\mathrm{asb} \neq}$ & $202.4 \pm 23.4^{\mathrm{asb} s c^{*}}$ \\
\hline$H D L_{2 b}(m g / L)$ & $379.8 \pm 57.8$ & $319.3 \pm 46.6^{\mathrm{a} \S}$ & $255.3 \pm 27.3^{\mathrm{a} s \mathrm{~b}}$ & $219.3 \pm 26.5^{\text {asbsc } f}$ \\
\hline
\end{tabular}

Values are expressed as Mean \pm S.D.

${ }^{*} P<0.05,{ }^{\ddagger} P<0.01,{ }^{\S} P<0.001$.

${ }^{\text {a }}$ Significantly different from Normal TG group.

${ }^{\text {b}}$ Significantly different from Borderline-high TG group.

'Significantly different from High TG group.

sized particles pre $\beta_{1}$-HDL, HDL $\mathrm{H}_{3 \mathrm{a}}$ were significantly increased, whereas there was a significant reduction in the contents of large-sized particles $\mathrm{HDL}_{2 \mathrm{a}}$, and $\mathrm{HDL}_{2 \mathrm{~b}}$ with the increased of TG levels. Furthermore, the contents of other HDL subclasses had no marked difference in borderline-high, high and very high TG subjects vs. the corresponding normal TG subjects.

Relations of the pre $\beta_{1}-\mathrm{HDL}$ and $\mathrm{HDL}_{2 \mathrm{~b}}$ contents to the levels of TG

To investigate the degree of HDL subclasses change with the levels of TG varied, we divided the levels of TG into 9 strata and using each stratum TG median value as $\mathrm{x}$ axis, with every stratum TG corresponding the median pre $\beta_{1}$-HDL and $\mathrm{HDL}_{2 \mathrm{~b}}$ contents as y axis to plot (Figure 1). The figure shows associations of TG levels with increased pre $\beta_{1}$-HDL contents and with decreased $\mathrm{HDL}_{2 \mathrm{~b}}$ contents.

Profile of pre $\beta_{1}-\mathrm{HDL}$ and $\mathrm{HDL}_{2 b}$ contents distribution in accordance with the TG together with ApoA-I levels Regardless of elevated TG and/or apoA-I, pre $\beta_{1}$-HDL contents were obviously increased Figure 2(1); The similar results observed that in each same TG group, $\mathrm{HDL}_{2 \mathrm{~b}}$ contents were marginally elevated accompanied with the increase of apoA-I levels. On the contrary, in any apoAI levels, contents of $\mathrm{HDL}_{2 \mathrm{~b}}$ were apparently decreased as the elevation of TG levels. Moreover, the lowest

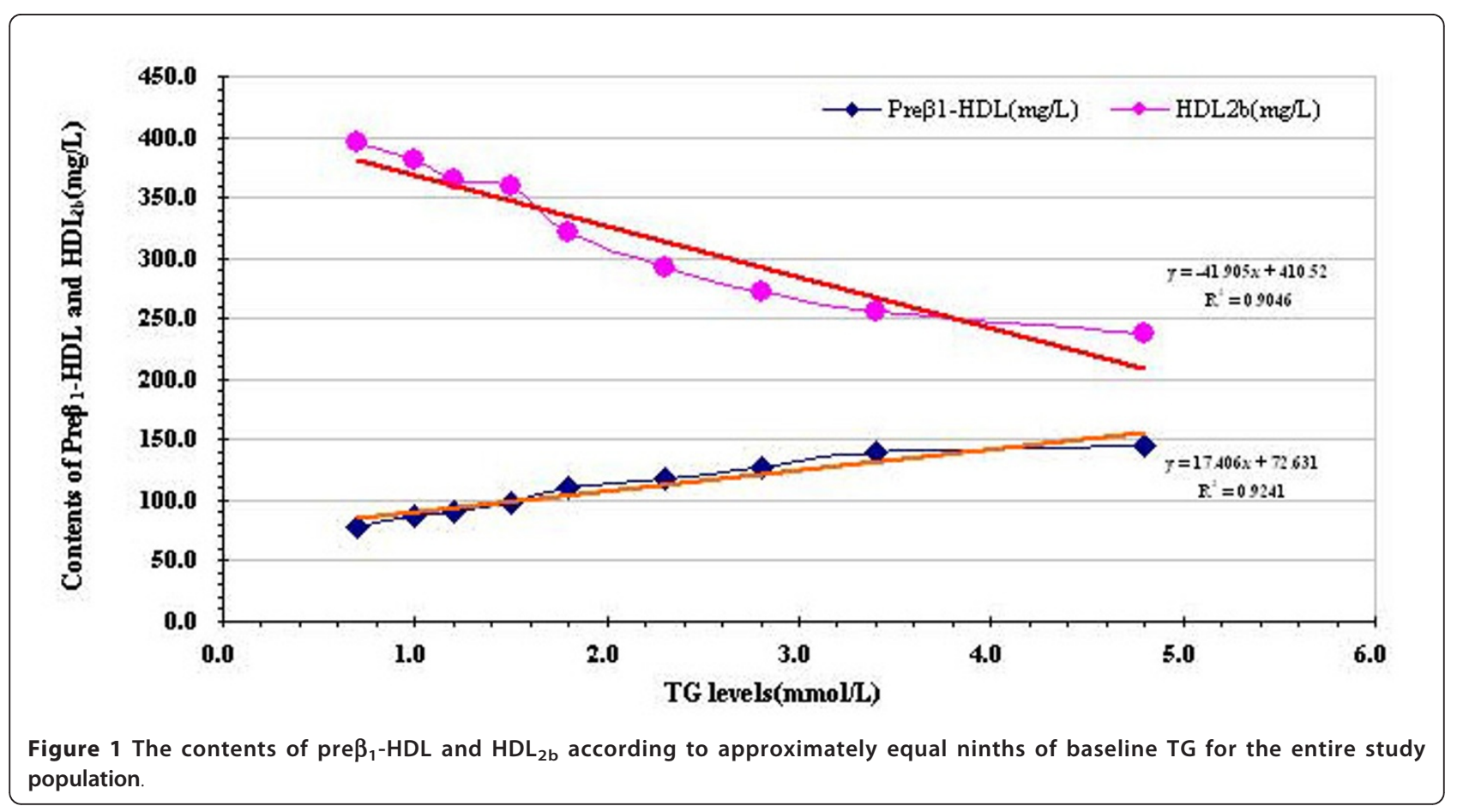


contents of $\mathrm{HDL}_{2 \mathrm{~b}}$ occurred in the very high TG-low apoA-I group $(152.2 \pm 23.8 \mathrm{mg} / \mathrm{L})$ in terms of the graphic information represented in Figure 2(2).

\section{Changes of pre $\beta_{1}-\mathrm{HDL}$ and $\mathrm{HDL}_{2 \mathrm{~b}}$ contents distribution} based on the levels of TG and ApoB-100/A-I ratio

We use a suggested cut-point value of 0.9 for the apoB100/apoA-I ratio to further dichotomized analyze the effect of TG concentration combined with ApoB-100/AI ratio on profile of pre $\beta_{1}-\mathrm{HDL}$ and $\mathrm{HDL}_{2 \mathrm{~b}}$ distribution
[Figure 3(A) and 3(B)]. The results presented that both of apoB-100/A-I $<0.9$ and apoB-100/A-I $\geq 0.9$ groups, the contents of pre $\beta_{1}$-HDL were increased significantly while the contents of $\mathrm{HDL}_{2 \mathrm{~b}}$ were obviously lower with a rise in TG concentrations.

It is noteworthy, the reduction of $\mathrm{HDL}_{2 \mathrm{~b}}$ contents $(151.0 \pm 21.3 \mathrm{mg} / \mathrm{L})$ even exceed the elevation of $\operatorname{pre}_{1}$ HDL contents $(183.9 \pm 28.7 \mathrm{mg} / \mathrm{L})$ which resulted in a reduction of $\mathrm{HDL}_{2 \mathrm{~b}} / \mathrm{pre}_{1}$-HDL ratio (0.8) for subjects with very high TG-ApoB-100/A-I $\geq 0.9$.

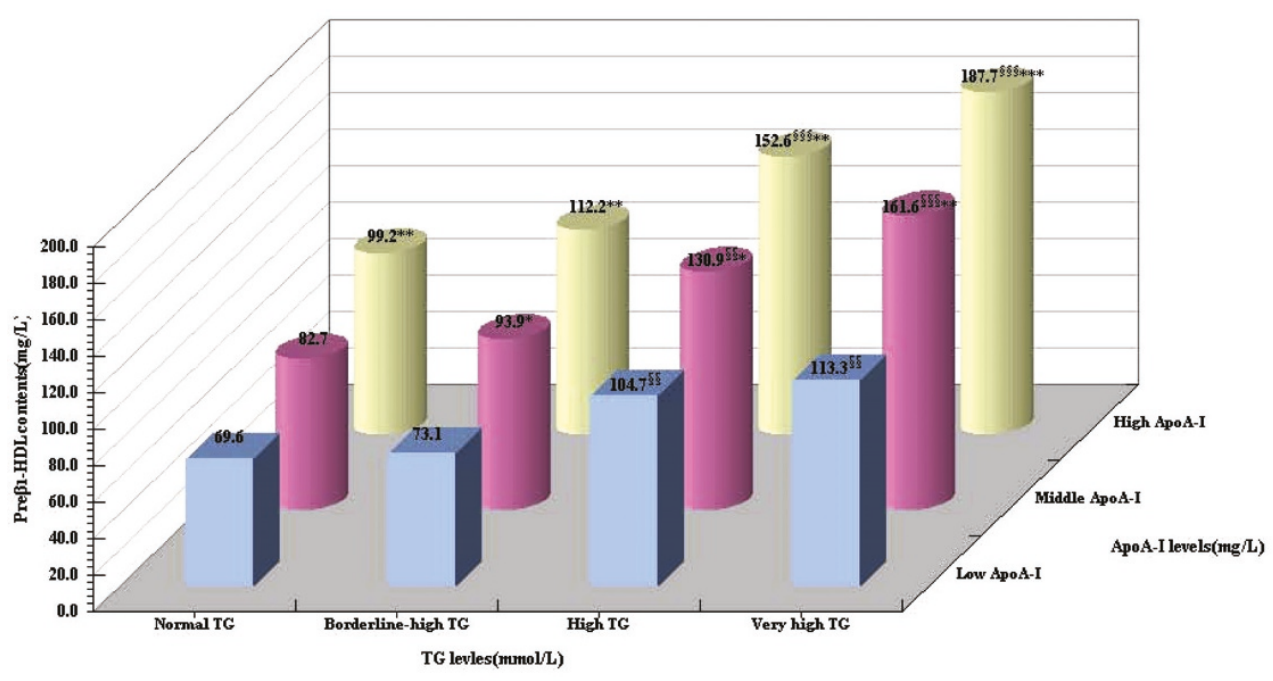

(1)

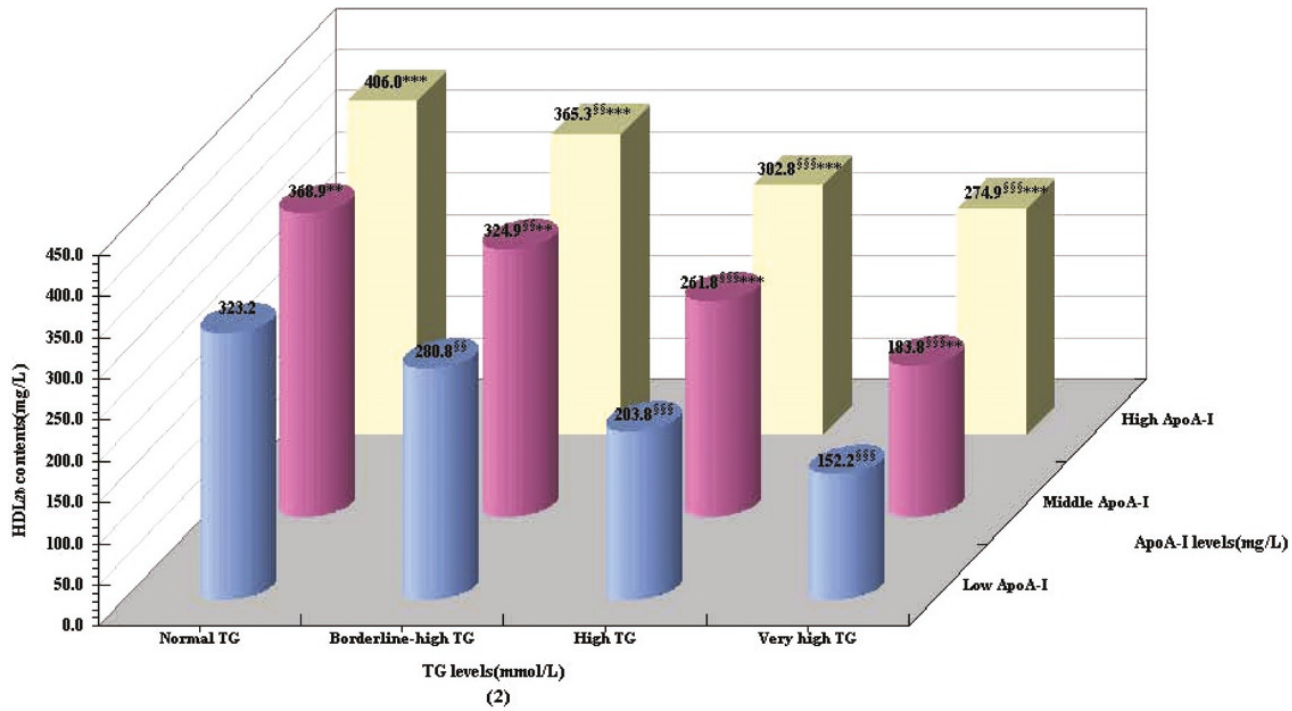

Figure 2 The contents of pre $\beta_{1}-\mathrm{HDL}(1)$ and $\mathrm{HDL}_{2 \mathrm{~b}}(2)$ according to TG and apoA-I concentration for the whole subjects. ${ }^{*} P<0.05,{ }^{* *} P<$ 0.01 , ${ }^{* * *} P<0.001$, compared with the low apoA-I subgroup within the same TG group ${ }^{\S \S} P<0.01,{ }^{\S \S} P<0.001$, compared with the normal TG subgroup within the same apoA-I group. 


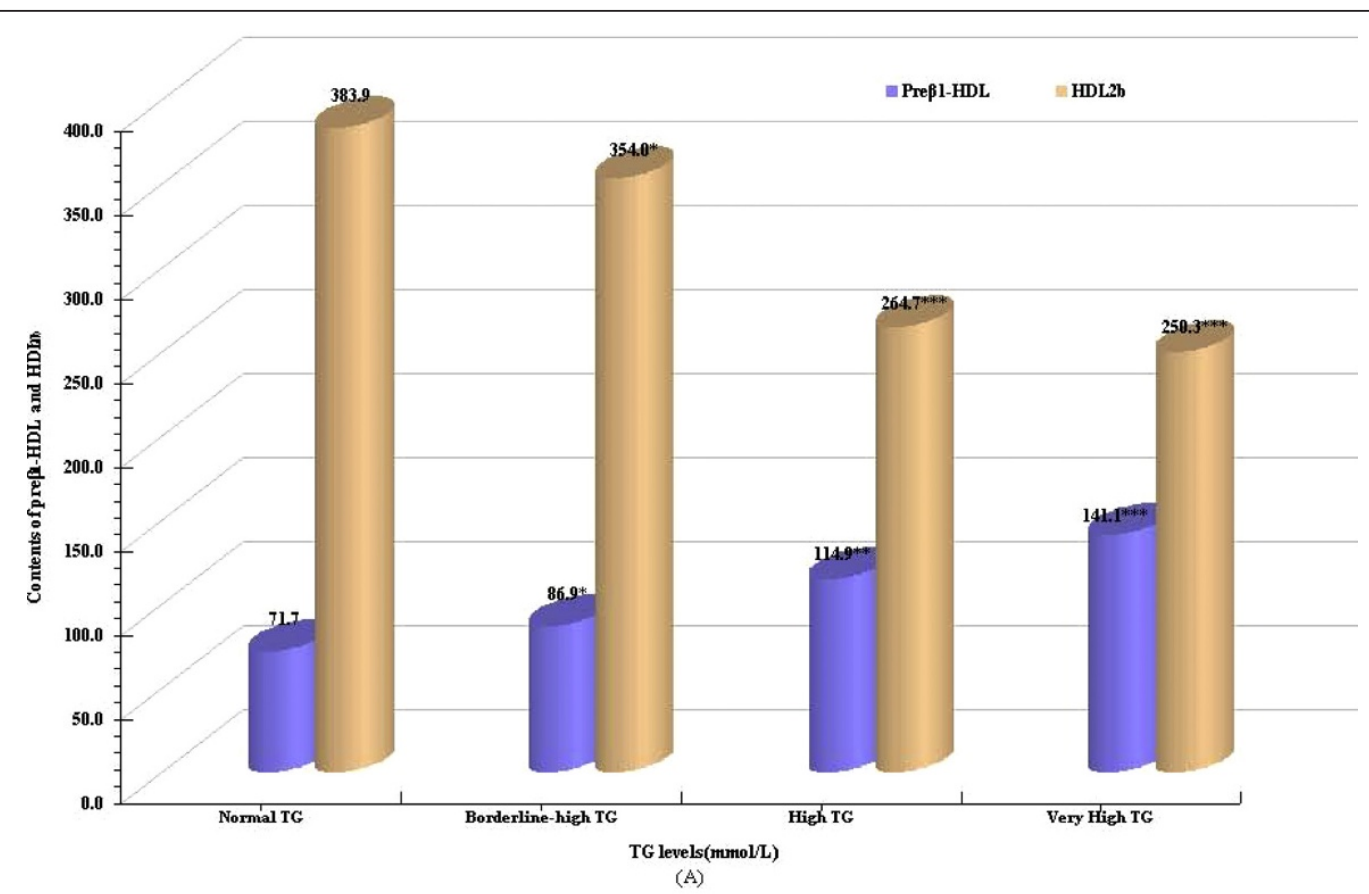

(A)

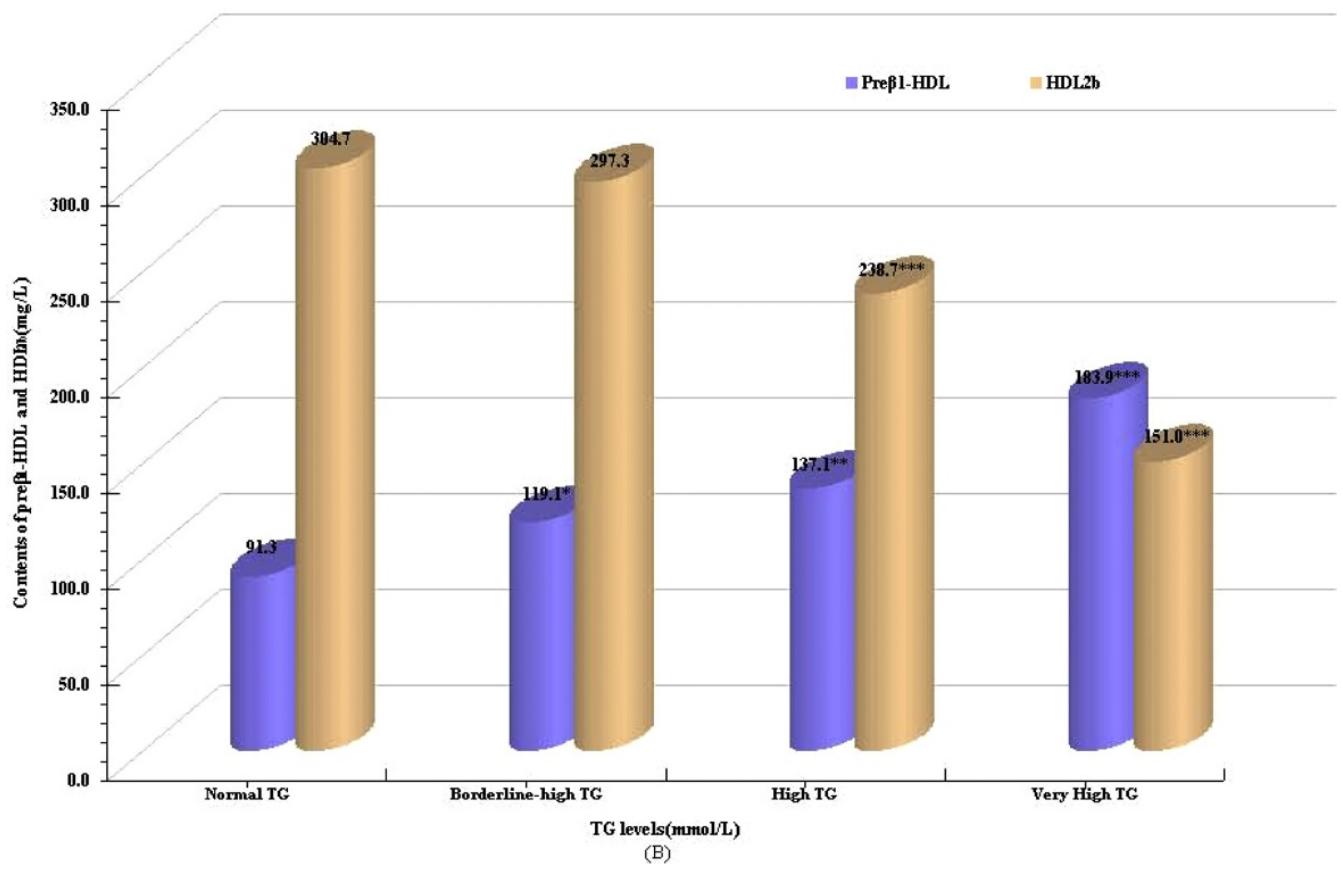

Figure 3 The contents of pre $\beta_{1}-\mathrm{HDL}$ and $\mathrm{HDL}_{2 b}$ for TG combine with apoB-100/A-I(A) and TG combine with apoB-100/A-I(B), respectively. ${ }^{*} P<0.05,{ }^{*} P<0.01,{ }^{* * *} P<0.001$, compared with the normal TG subgroup.

The correlations analysis between plasma lipids, lipids ratios, and the contents of $\mathrm{HDL}$ subclasses after controlling for apoA-I, apoB-100

Table 3 shows correlations between the contents of HDL subclasses and conventional lipid parameter when controlling for apoA-I, and apoB-100. Specifically, the concentrations of TG, TC, LDL-C, and the ratios of TG/HDL-C, TC/HDL-C, as well as LDL-C/HDL-C were highly positively correlated with $\operatorname{pre}_{1}-\mathrm{HDL}$ and $\mathrm{HDL}_{3 \mathrm{a}}$ while being negatively associated with HDL-C 
Table 3 Correlation coefficients between plasma lipids, lipids ratios and HDL subclasses contents (Controlling for ApoA-I, ApoB-100)

\begin{tabular}{|c|c|c|c|c|c|c|c|c|c|c|c|c|c|c|}
\hline & \multicolumn{2}{|l|}{ TG } & \multicolumn{2}{|l|}{$\mathrm{TC}$} & \multicolumn{2}{|l|}{ LDL-C } & \multicolumn{2}{|c|}{ HDL-C } & \multicolumn{2}{|c|}{ TG/HDL-C } & \multicolumn{2}{|c|}{ TC/HDL-C } & \multicolumn{2}{|c|}{ LDL-C/HDL-C } \\
\hline & $\mathrm{t}$ & $P$ & $\mathrm{t}$ & $P$ & $\mathrm{t}$ & $P$ & $t$ & $P$ & $\mathrm{t}$ & $P$ & $\mathrm{t}$ & $P$ & $\mathrm{t}$ & $P$ \\
\hline Pre $\beta_{1}-\mathrm{HDL}$ & .448 & .000 & .186 & .000 & .006 & .897 & -.269 & .000 & .439 & .000 & .374 & .000 & .152 & .001 \\
\hline Pre $\beta_{2}-\mathrm{HDL}$ & .147 & .001 & .029 & .525 & .047 & .301 & -.052 & .254 & .141 & .001 & .114 & .012 & .035 & .446 \\
\hline $\mathrm{HDL}_{3 \mathrm{c}}$ & .011 & .209 & .099 & .028 & .063 & .164 & .083 & .067 & .025 & .587 & .021 & .643 & .005 & .912 \\
\hline $\mathrm{HDL}_{3 \mathrm{~b}}$ & .006 & .899 & .183 & .000 & .176 & .000 & -.030 & .507 & .005 & .915 & .116 & .011 & .147 & .001 \\
\hline $\mathrm{HDL}_{3 a}$ & .288 & .000 & -.119 & .009 & -.176 & .000 & -.253 & .000 & .314 & .000 & .233 & .000 & .065 & .156 \\
\hline $\mathrm{HDL}_{2 \mathrm{a}}$ & -.211 & .000 & .059 & .192 & .097 & .033 & .207 & .000 & -.214 & .000 & -.164 & .000 & .049 & .280 \\
\hline $\mathrm{HDL}_{2 \mathrm{~b}}$ & -.296 & .000 & -.146 & .001 & -.019 & .674 & .281 & .000 & -.314 & .000 & -.310 & .000 & -.165 & .000 \\
\hline
\end{tabular}

concentration. The contents of $\mathrm{HDL}_{2 \mathrm{a}}$ and $\mathrm{HDL}_{2 \mathrm{~b}}$ were inversely associated with $\mathrm{TG}$ and the ratios of TG/HDLC, TC/HDL-C along with LDL-C/HDL-C but positively related to $\mathrm{HDL}-\mathrm{C}$ concentration. With respect to other HDL subclasses, the concentrations of TG, TC, LDL-C, and the ratios of TC/HDL-C, LDL-C/HDL-C were positively correlated with $\mathrm{HDL}_{3 \mathrm{~b}}$.

\section{Discussion}

Many prospective studies have reported a positive relationship between levels of TG and incidence of CHD $[19,20]$. However; early multivariate analyses generally did not identify plasma TG as an independent risk factor for CHD [21]. Lipoprotein metabolism is integrally linked with, and elevations of plasma TG can be confounded by significant correlations with LDL and HDL-C levels. Nonlipid risk factors of obesity, cigarette smoking also integrated with TG as are several emerging risk factors [22]. Therefore, many persons with elevated TG are at increased risk for CHD, even when this greater risk can not be independently explained by TG.

It is well known that the most common hyperlipidemia for the Chinese population was characterized by elevated TG levels, which was much more prevalent (61\% of total hyperlipidemia) than high TC [11]. Liu [23] suggested that higher levels of TG in China were induced by high-carbohydrate diets of the populations. Sugars and grains require insulin secretion, which is a potent stimulus to the liver to produce TG. We assessed the alteration of TG levels by Adult Treatment Panel III (ATP-III) guidelines [24] and HDL subclasses particle size using two-dimensional electrophoresis immunodetection. The data displayed that with the elevation of TG levels, the subjects have an atherogenic dyslipidemia phenotype comprising of an increased of TG, TC, LDL$\mathrm{C}$ and apoB-100,C-II, C-III along with the ratios of TG/ HDL-C, TC/HDL-C,LDL-C/HDL-C, and apoB-100/A-I, coupled with a decreased of HDL-C, apoA-I as well as apoC-III/C-II ratio. Meanwhile, elevated TG concentrations were related to the higher contents of small-sized (pre $\beta_{1}-\mathrm{HDL}$ and $\mathrm{HDL}_{3 \mathrm{a}}$ ) and the lower contents of large-sized $\mathrm{HDL}\left(\mathrm{HDL}_{2 \mathrm{a}}\right.$ and $\left.\mathrm{HDL}_{2 \mathrm{~b}}\right)$. Further, for grouped analyses, individuals were classified according to approximately equal ninths of baseline TG for the entire study population (_0.7, 0.8-1.0, 1.1-1.4, 1.5-1.8, 1.9-2.3, 2.4-2.8, 2.9-3.4, 3.5-4.8, and $\geq 4.8 \mathrm{mmol} / \mathrm{l})$. Trends in mean values of major HDL subclasses $\left(p r e \beta_{1}\right.$ $\mathrm{HDL}$ and $\mathrm{HDL}_{2 \mathrm{~b}}$ ) across these ninths were assessed through simple linear regression, in this models with the contents of pre $\beta_{1}-\mathrm{HDL}$ and $\mathrm{HDL}_{2 \mathrm{~b}}$ as the dependent variable and the levels of TG levels as independent variable, our results revealed that pre $\beta_{1}$-HDL contents is elevated about $9 \mathrm{mg} / \mathrm{L}$ and $\mathrm{HDL}_{2 \mathrm{~b}}$ contents can be reduced $21 \mathrm{mg} / \mathrm{L}$ for $0.5 \mathrm{mmol} / \mathrm{L}$ increment in TG.

Many studies have established that with the elevation of plasma TG concentration and the reduction of HDL$C$ concentration, cholesteryl ester transfer protein (CETP) and hepatic lipase (HL) activities were strengthen[25]. Through the actions CETP, intravascular exchange of neutral lipids and apos occurs between apoB-containing lipoprotein(LDL), intermediate density lipoprotein (IDL), very low density lipoprotein (VLDL), chylomicrons (CM), and remnants and HDL. Thus, elevated TG leads to the generation of TG-rich HDL particles, which are more susceptible to modification by HL [26]. HL has greater activity against HDL and converts larger HDL particles to smaller HDL particles. The higher concentration TG and the lower concentration of HDL-C associated with increased HDL catabolism, another is a reduction in lipoprotein lipase (LPL) and lecithin cholesterolacyl transferase (LCAT) activities. The activity of LCAT catalyzes the transfer of 2-acyl groups from lecithin to free cholesterol (FC), generating cholesterol ester (CE) and lysolecithin. Hydrophobic CE is retained in the $\mathrm{HDL}$ core forming larger mature $\mathrm{HDL}$ particles [27]. LPL has predominantly TG lipase activity, In the process of hydrolyzing TG-rich lipoprotein(TRL), CM and VLDL release TG, TC, phospholipids, apoA-I and apoCs, subsequent binding of these products to $\mathrm{HDL}_{3}$ results in formation of $\mathrm{HDL}_{2}$ particles. This modification leads to the formation of smaller HDL particles, which may impair its cardioprotective function. 
Another important metabolic trigger for HDL mature metabolic disorder in the elevated TG concentrations condition could be involved in the plasma apolipoprotein levels alter. We divided the apoA-I concentrations into tertiles and to investigate the influence of TG combined with apoA-I levels on phenotype of HDL subclasses distribution. Our findings presented that regardless of elevated TG and/or apoA-I, pre $\beta_{1}$-HDL contents were obviously increased; Likeness, in any TG levels, the contents of $\mathrm{HDL}_{2 \mathrm{~b}}$ significantly and gradually increased with elevated of apoA-I levels, which suggested that the protective effect of increased apoA-I levels against the reduction of $\mathrm{HDL}_{2 \mathrm{~b}}$ caused by elevated TG concentration. Other researchers have found that during severe sepsis or chronic inflammation, proinflammatory cytokine and TG levels are increased, while Apo-AI, Apo-B levels are decreased [28-31]. Cytokines have a major role in stimulating the production of acute phase proteins (APP) as part of the host immune response to infection, but prolonged inflammatory immune responses may be harmful to the host. Like albumin, Apo-AI is classified as a negative APP. While the role of negative APP is unclear, reduced levels of negative APP with anti-inflammatory activity, such as Apo-AI and transthyretin, may promote pro-inflammatory responses [32].

Studies in human apoA-I transgenic mice have showed that the distribution of apoA-I among the HDL subclasses was similar, suggesting that the content of apoA-I in the major HDL subspecies was fixed [33] and the apoA-I levels might reflect of the amount or number of HDL particles, and with the elevation of apoA-I levels, molecules of apoA-I distributed to each of the subclasses increased which resulted in all HDL subclasses tend to increase. In addition, apoA-I not only is activator of LCAT but also is a critical ligand of the HDL receptor scavenger receptor $B I(S R-B I)$ and the interaction of apoA-I and SR-BI may facilitate hepatic selective uptake of HDL-C in the RCT pathway. In agreement with these, our previous study have reported that with increased plasma apoA-I concentration, the contents of all HDL subclasses rose significantly, with the increase in large-sized $\mathrm{HDL}_{2 \mathrm{~b}}$ being the most significant.

The large prospective apolipoprotein-related Mortality Risk (AMORIS) study [34] suggests that apoB-100, apoA-I and the apoB-100/apoA-I ratio should be regarded as highly predictive in evaluating cardiac risk $[34,35]$. A series of studies have shown that an apoB100 /apoA-I ratio $\geq 0.9$ was a fair predictor of presence of the metabolic syndrome (MetS) [36], and men with an apoB-100/apoA-I ratio $>0.9$ had also a faster growth of carotid artery intima-media thickness (IMT) than those below this value [37]. In the previous work, we use a 0.9 cut-point for the apoB-100/A-I ratio to dichotomized analyze the alteration of HDL subclasses distribution and found that pre $\beta_{1}$-HDL contents were higher while $\mathrm{HDL}_{2 \mathrm{a}}, \mathrm{HDL}_{2 \mathrm{~b}}$ contents were lower for subjects with apoB-100/apoA-I ratio $\geq 0.9$ than that for subjects with apoB-100/apoA-I ratio $<0.9$, which suggests that apoB100/A-I ratio might be a strong marker to HDL subclasses distribution, moreover, it could reflect sensitivity the alteration of $\mathrm{HDL}_{2 \mathrm{~b}} / \mathrm{pre}_{1}$-HDL values[38].

On the basis of this, we further discussed the effect of TG interact with apoB-100/apoA-I ratio $\geq 0.9$ and apoB-100/apoA-I ratio $<0.9$, separately on HDL subclasses distribution. The results obtained in the present work presented that, the pre $\beta_{1}$-HDL contents increased significantly and the $\mathrm{HDL}_{2 \mathrm{~b}}$ contents decreased significantly as the elevation of TG concentration despite the subjects with the apoB-100/apoA-I ratio < 0.9. At the same time, in comparison with the normal TG, the marked lower values of $\mathrm{HDL}_{2 \mathrm{~b}} / \mathrm{pre}_{1}$ - $\mathrm{HDL}$ in both high and very high TG groups (5.3 vs $2.3,1.7)$. Similarly, in the apoB-100/apoA-I ratio $\geq 0.9$, the HDL subclasses distribution might be reversed for subjects with normal TG concentration. A low $\mathrm{HDL}_{2 \mathrm{~b}} / \mathrm{pre}_{1}$ HDL ratio is a signature type of disturbed HDL metabolism and RCT and the cholesterol balance determined as the apoB-100/apoA-I ratio has repeatedly been shown to be a better index for risk assessment of CHD. The higher the value of the apoB-100/apoA-I ratio, the more cholesterol is circulating in the plasma compartment and this cholesterol is likely to be deposited in the arterial wall, provoking atherogenesis and risk of coronary vascular $(\mathrm{CV})$ events. From the point of view of HDL subclasses distribution, all these findings revealed that when evaluation the CHD risk, relying only on apoB-100/apoA-I values for subjects might be inadequate and the concentration of TG should be concerned.

Besides, it is interesting to find that despite the levels of apoC-II and apoC-III increased, and an increasing in apoC-II more prominent than in apoC-III which conduces to the apoC-III/C-II ratio declined accompany with the elevation of TG concentration (Table 1). Sasaki, et al [39]. reported that high carbohydrate feedings caused decreased HDL-C and apoA-I concentrations were associated with reduced levels of apoC-III but increased concentrations of apoC-II in $\mathrm{HDL}_{2}$. In vitro investigation have exhibited that high levels of apoC-II have inhibited LPL activity rather than stimulated it [40]. The diets high in carbohydrate are prevalent in China, which may result in disorder of TG metabolism (excessive production and/or deficient clearance) Based on this, the high carbohydrate diets induced HTG usually accompanied with the apoC-III/C-II ratio decreasing, and the apoC-III/C-II ratio seems to play an 
important part in HDL subclasses maturation among Chinese population.

\section{Conclusions}

In summary, we have shown that the particle size of HDL subclasses tend to small with increasing TG concentration which indicated that HDL maturation might be impeded and efficiency of RCT might be weakened. These data suggest that TG levels were not only significantly associated with but liner with the contents of pre $\beta_{1}-\mathrm{HDL}$ and $\mathrm{HDL}_{2 \mathrm{~b}}$. They also raise the possibility that TG levels effect on HDL maturation metabolism are subjected to plasma apos and apos ratios.

\section{Methods}

\section{Subjects}

Five hundred subjects (325 men; mean age, $56.3 \pm$ 7.2 years; 175 women; mean age, $56.5 \pm 8.1$ years) were recruited to participate in a study examining plasma lipid and apo concentrations at West China Medical Center, Sichuan University. Exclusion criteria were the following: (1) the presence of nephrosis, diabetes mellitus, hypothyroidism, or hepatic impairment; (2) the presence of a major cardiovascular event (myocardial infarction, severe or unstable angina pectoris, and surgery) or stroke; (3) taking lipid-altering medications in the previous 1 month; or (4) a history of alcohol abuse and smoking cigarettes. Women were excluded if they had undergone a hysterectomy with or without an oophorectomy, or were postmenopausal and receiving hormone replacement therapy. Informed consent was obtained from each subject upon entry into the study population. This study protocol was approved by the ethics committee.

To study the TG role in the profile of HDL subclasses distribution, we divided these subjects into four subgroups according to plasma TG levels, that is normal (< $1.69 \mathrm{mmol} / \mathrm{L})$, borderline-high $(1.69-2.25 \mathrm{mmol} / \mathrm{L})$, high $(2.26-5.64 \mathrm{mmol} / \mathrm{L})$, and very high $(\geq 5.65 \mathrm{mmol} / \mathrm{L})$ which were defined by following guidelines from the ATP-III of the National Cholesterol Education Program (NCEP) [24]. Moreover, the change in apoA-I, and apoB-100/A-I ratio associated with the phenotype of HDL subclass distribution were also investigated in the current work. The apoA-I concentration was entered as a categorical variable with three levels. Firstly, the apoAI was arranged in ascending sequence on basis of its concentrations, next the number first to 167th subjects were designated as lowest tertile of apoA-I group; 168th to 334th subjects were designated as middle tertile of apoA-I group, and the 335th to 500th subjects were designated as the highest tertile of apoA-I group.

\section{Specimens}

Whole blood specimens were drawn after a 12-hour overnight fast into EDTA-containing tubes. Plasma was separated within 1-2 hours. Plasma was stored at $4{ }^{\circ} \mathrm{C}$ and used within 24 hour for lipid and apolipoprotein analyses. An aliquot of plasma was stored at $-70^{\circ} \mathrm{C}$ for the determination of HDL subclasses.

\section{Plasma lipid and apolipoprotein analyses}

Plasma TG, TC and HDL-C were measured by standard technique. TC and TG were determined with enzymatic kits (Beijing Zhongsheng Biotechnological Corporation, Beijing). HDL-C was determined after precipitation of the apoB-containing lipoproteins by phosphotungstate/magnesium chloride [41]. LDL-C was calculated using Friedwald formula (TG $<4.52$ $\mathrm{mmol} / \mathrm{L}$ ) [42]. When plasma $\mathrm{TG} \geq 4.52 \mathrm{mmol} / \mathrm{L}$, LDL$\mathrm{C}$ was determined following precipitation method with polyvinylsulfate (enzymatic kits). Plasma apoA-I, B-100 were determined by radial immunodiffusion methods [43] using kits developed at the apolipoprotein Research Laboratory, West China medical Center, Sichuan University. The intra-assay coefficient variations for apolipoprotein concentrations were between 2.1 and $4.8 \%$, inter-assay coefficient of the variations was 3.5 to $7.9 \%$ [44].

\section{High-density lipoprotein cholesterol subclass analyses}

ApoA-I-containing HDL subclasses were measured by nondenaturing two-dimensional gel electrophoresis associated with immunodetection method as described previously [45]. Briefly, $10 \mu \mathrm{l}$ of plasma was first separated by charge on $0.7 \%$ agarose gel, into pre $\beta$ and $\alpha$ mobility particles. In the second dimension, the 2 fractions of HDL were further separated according to size by $2-30 \%$ nondenaturing polyacrylamide gradient gel electrophoresis. To determine HDL subclasses, western blotting was conducted after electrophoresis, using horseradish peroxidase (HRP)-labeled goat anti-human apoA-I immunoglobulin G (IgG). HDL particle sizes were calibrated using a standard curve that includes bovine serum albumin, ferritin and thyroglobulin (Pharmacia Uppsala, Sweden). The calculation of each HDL subclass relative percentage (\%) was based on the density of electrophoresis spots. Then the apoA-I contents $(\mathrm{mg} / \mathrm{L})$ of the HDL subclasses were calculated by multiplying the percentage of each subclass by the plasma total apoA-I concentrations. The inter-assay coefficient of variations of the relative concentration of pre $\beta_{1}-\mathrm{HDL}$, pre $\beta_{2}-\mathrm{HDL}$, $\mathrm{HDL}_{3 \mathrm{c}}, \mathrm{HDL}_{3 \mathrm{~b}}, \mathrm{HDL}_{3 \mathrm{a}}, \mathrm{HDL}_{2 \mathrm{a}}$, and $\mathrm{HDL}_{2 \mathrm{~b}}$ in plasma sample were $9.4 \%, 9.8 \%, 4.9 \%, 6.2 \%, 7.3 \%, 11.1 \%$ and $7.9 \%$, respectively $(n=5)$. 


\section{Statistical analysis}

All statistical analysis was performed using the statistical package SPSS Version 11.0 (SPSS Inc). Data are expressed as mean \pm S.D. The significant differences between two groups were analyzed by one-way analysis of variance (ANOVA). Linear regression was used to examine the associations between plasma lipids, lipids ratios and other variables. In all comparisons, $P<0.05$ (2-sided) was regarded as statistically significant.

\section{Acknowledgements}

We thank technician Yu Liu and master's students Jia Yao and Xuemei Zhang for the collection of the blood samples and technical support in lipid and apolipoprotein assays.

\section{Conflict of Interest Statement}

The authors declare that they have no conflict of interest.

\section{Notice of grant support}

The authors thank the Fundamental Research Funds for the Central Universities (No. 2010SCU11029) for the grant support of this work.

\section{Author details}

${ }^{1}$ Laboratory of Endocrinology and Metabolism, West China Hospital, Sichuan University, Chengdu 610041, Sichuan, People's Republic of China. ${ }^{2}$ Chengdu Hoist Biotechnology Co.,LTD, Chengdu 610075, Sichuan, PR China. ${ }^{3}$ Chengdu University Affiliated Hospital of Traditional Chinese Medicine, Chengdu 610072, Sichuan, PR China. ${ }^{4}$ Department of Biochemistry and Molecular Biology, University of South China, Hengyang, Hunan, People's Republic of China.

Received: 7 December 2010 Accepted: 21 January 2011

Published: 21 January 2011

\section{References}

1. Miller GJ, Miller NE: Plasma-high-density-lipoprotein concentration and development of ischaemic heart-disease. Lancet 1975, 305:16-19.

2. Vega GL, Grundy SM: Hypoalphalipoproteinemia (low high density lipoprotein) as a risk factor for coronary heart disease. Curr Opin Lipidol 1996, 7:209-216.

3. Watanabe $H$, Söderlund $S$, Soro-Paavonen A, Hiukka A, Leinonen $E_{\text {, }}$ Alagona C, Salonen R, Tuomainen TP, Ehnholm C, Jauhiainen $M$, Taskinen MR: Decreased high-density lipoprotein (HDL) particle size, preß-, and large HDL subspecies concentration in Finnish low-HDL families: relationship with intima-media thickness. Arterioscler Thromb Vasc Biol 2006, 26:897-902.

4. Nakanishi S, Vikstedt R, Söderlund S, Lee-Rueckert M, Hiukka A, Ehnholm C, Miulu M, Metso J, Naukkarinen J, Palotie L, Kovanen PT, Jauhiainen M, Taskinen MR: Serum, but not monocyte macrophage foam cells derived from low HDL-C subjects, displays reduced cholesterol efflux capacity. J Lipid Res 2009, 50:183-192.

5. Pascot A, Lemieux I, Prud'homme D, Tremblay A, Nadeau A, Couillard C, Bergeron J, Lamarche B, Després JP: Reduced HDL particle size as an additional feature of the atherogenic dyslipidemia of abdominal obesity. J Lipid Res 2001, 42:2007-2014.

6. Soro-Paavonen A, Westerbacka J, Ehnholm C, Taskinen MR: Metabolic syndrome aggravates the increased endothelial activation and lowgrade inflammation in subjects with familial low HDL. Ann Med 2006, 38:229-238.

7. Huang RC, Mori TA, Burke V, Newnham J, Stanley FJ, Landau LI, Kendall GE, Oddy WH, Beilin LJ: Synergy between adiposity, insulin resistance, metabolic risk factors, and inflammation in adolescents. Diabetes Care 2009, 32:695-701.

8. Johansson J, Carlson LA, Landou C, Hamsten A: High density lipoprotein and coronary atherosclerosis. A strong inverse relation with the largest particles is confined to normotriglyceridemic patients. Arterioscler Thromb Vasc Biol 1991, 11:174-182

9. Shuhei N, SÖderlund S, jauhiainen M, Taskinen MR: Effect of HDL composition and particle size on the resistance of HDL to the oxidation. Lipids in Health and Disease 2010, 9:104.

10. Von Eckardstein A, Huang Y, Assmann G: Physiological role and clinical relevance of high-density lipoprotein subclasses. Curr Opin Lipidol 1994, 5:404-416

11. Wu XW, Fu MD, Liu BW: Study on the immunodetection method of HDL subclasses in human serum. Chin J Arterioscler 1999, 7:253-255.

12. $\mathrm{Xu}$ YH, Fu MD: Alterations of HDL subclasses in hyperlipidemia. Clin Chim Acta 2003, 332:95-102.

13. Kontush A, Chapman MJ: Antiatherogenic small, dense HDL-guardian angel of the arterial wall? Nat Clin Pract Cardiovasc Med 2006, 3:144-153.

14. Asztalos BF, Cupples LA, Demissie S, Horvath KV, Cox CE, Batista MC, Schaefer EJ: High-density lipoprotein subpopulation profile and coronary heart disease prevalence in male participants of the Framingham Offspring Study. Arterioscler Thromb Vasc Biol 2004, 24:2181-2187.

15. Cheung MC, Brown BG, Wolf AC: Altered particle size distribution of apoA-I-containing HDL subpopulations in patients with coronary heart disease. J lipid Res 1991, 32:383-394.

16. Yang YY, Yan BY, Fu MD, Tian Y: Relationship between plasma lipid concentrations and HDL subclasses. Clin Chim Acta 2005, 354:49-58.

17. Gou LT, Fu MD, Xu YH, Tian Y, Yan BY: Alterations of HDL subclasses in endogenous hypertriglyceridemia. Am Heart J 2005, 150:1039-1045.

18. Jia LQ, Fu MD, Tian Y, XU YH, Gou LT, Tian HM, Tian L: Alterations of highdensity lipoprotein subclasses in hypercholesterolemia and combined hyperlipidemia. Int J Cardiol 2007, 120:331-337.

19. Austin MA, Hokanson JE, Edwards KL: Hypertriglyceridemia as a cardiovascular risk factor. Am J Cardiol 1998, 81:7B-12B.

20. Assmann G, Schulte $H$, Funke $H$, Von Eckardstein A: The emergence of triglycerides as a significant independent risk factor in coronary artery disease. Eur Heart J 1998, 19:M8-M14.

21. Hulley SB, Rosenman RH, Bawol RD, Brand RJ: Epidemiology as a guide to clinical decisions:the association between triglyceride and coronary heart disease. N Engl J Med 1980, 302:1383-1389.

22. Grundy SM: Hypertriglyceridemia, atherogenic dyslipidemia, and the metabolic syndrome. Am J Cardiol 1998, 81:18B-25B.

23. Liu BW: Study on the pathogenesis of endogenous hypertriglyceridemia. Chin J Arterioscler 1993, 1:67-69.

24. Executive Summary of The Third Report of The National Cholesterol Education Program (NCEP) Expert Panel: On Detection, Evaluation, And Treatment of High Blood Cholesterol In Adults (Adult Treatment Panel III). JAMA 2001, 285:2486-2497.

25. Rye KA, Clay MA, Barter PJ: Remodeling of high density lipoproteins by plasma factors. Atherosclerosis 1999, 145:227-238.

26. Packard CJ: Triacylglycerol-rich lipoproteins and the generation of small, dense low-density lipoprotein. Biochem Soc Trans 2003, 31:1066-1069.

27. Jonas A: Lecithin cholesterol acyltransferase. Biochim Biophys Acta 2000, 1529:245-256.

28. Beers A, Haas MJ, Wong NC, Mooradian AD: Inhibition of apolipoprotein Al gene expression by tumor necrosis factor alpha: roles for MEK/ERK and JNK signaling. Biochemistry 2006, 45:2408-2413.

29. Alvarez C, Ramos A: Lipids, lipoproteins, and apoproteins in serum during infection. Clin Chem 1986, 32:142-145.

30. Chenaud C, Merlani PG, Roux-Lombard P, Burger D, Harbarth S, Luyasu S, Graf JD, Dayer JM, Ricou B: Low apolipoprotein A-I level at intensive care unit admission and systemic inflammatory response syndrome exacerbation. Crit Care Med 2004, 32:632-637.

31. Khovidhunkit W, Kim MS, Memon RA, Shigenaga JK, Moser AH, Feingold KR, Grunfeld C: Effects of infection and inflammation on lipid and lipoprotein metabolism: mechanisms and consequences to the host. J Lipid Res 2004, 45:1169-1196.

32. Bresnihan B, Gogarty M, Fitzgerald O, Dayer JM, Burger D: Apolipoprotein A-I infiltration in rheumatoid arthritis synovial tissue: a control mechanism of cytokine production? Arthritis Res Ther 2004, 6:R563-R566.

33. Rubin EM, Ishida BY, Clift SM, Kranss RM: Expression of human apolipoprotein $\mathrm{A}-\mathrm{I}$ in transgenic mice results in reduced plasma levels of murine apolipoprotein A-I and the appearance of two new high density lipoprotein size subclasses. Biochemistry 1991, 88:434-438. 
34. Walldius G, Jungner I, Holme I, Aastveit AH, Kolar W, Steiner E: High apolipoproteinB, low apolipoprotein A-I, and improvement in the prediction of fatal myocardial infarction(AMORIS Study):a prospective study. Lancet 2001, 358:2026-2033.

35. Yusuf $P$, Hawken $S$, Ounpuu S, Dans T, Avezum A, Lanas F, McQueen M, Budaj A, Pais P, Varigos J, Lisheng L: Effect of potentially modifiable risk factors associated with myocardial infarction in 52 countries (the INTERGEART study):case-control study. Lancet 2004, 364:937-952.

36. Lind L, Vessby B, Sundström J: The apolipoproteinB/AI ratio and the metabolic syndrome independently predict risk for myocardial infarction in middle-aged men. Arterioscler Thromb Vasc Biol 2006, 26:406-410.

37. Wallenfeldt K, Bokemark L, Wikstrand J, Hulthe J, Fagerberg B: ApolipoproteinB/ApolipoproteinAI in relation to the metabolic syndrome and change in carotid artery intima-media thickness during 3 years in middle-aged men. Stroke 2004, 35:2248-2252.

38. Tian L, Wu XW, Fu MD, Qin Y, Xu YH, Jia LQ: Relationship between plasma apolipoproteinB concentrations, apolipoproteinB/apolipoproteinA-I and HDL subclasses distribution. Clin Chim Acta 2008, 388:148-155.

39. Sasaki N, Holdworth G, Barnhart RL, Srivastava LS, Glueck CS, Kashyap ML, Jackson RL: Effect of a high carbohydrate diet on the content of apolipoproteins $\mathrm{Cll}, \mathrm{CIII}$ and $\mathrm{E}$ in human plasma high density lipoprotein subfractions. Atherosclerosis 1983, 46:341-352.

40. Havel RJ, Fielding CJ, Olivecrona T, Shore VG, Fielding PE, Egelrud T: Cofactor activity of protein components of human very low density lipoproteins in the hydrolysis of triglycerides by lipoprotein lipase from different sources. Biochemistry 1973, 12:1828-1833.

41. Warnick GR, Nguyen T, Albers AA: Comparison of improved precipitation methods for quantification of high-density lipoprotein cholesterol. Clin Chem 1985, 31:217-222.

42. Friedewald WT, Levy Rl, Fredrickson DS: Estimation of the concentration of low-density lipoprotein cholesterol in plasma without the use of the preparative ultracentrifuge. Clin Chem 1972, 18:499-502.

43. Labeur C, Shepherd J, Rosseneu M: Immunological assays of apolipoproteins in plasma: methods and instrumentation. Clin Chem 1990, 36:591-597.

44. Liu BW: Immunoassay of human plasma apolipoproteins and clinical applications. In In: Lipoproteins and Atherosclerosis. Edited by: Wang KQ. Beijing, People's Health Press; 1995:359-368.

45. Fielding CJ, Fielding PE: Molecular physiology of reverse cholesterol transport. J Lipid Res 1995, 36:211-228.

doi:10.1186/1476-511X-10-17

Cite this article as: Tian et al:: The impact of plasma triglyceride and apolipoproteins concentrations on high-density lipoprotein subclasses distribution. Lipids in Health and Disease 2011 10:17.

\section{Submit your next manuscript to BioMed Central and take full advantage of:}

- Convenient online submission

- Thorough peer review

- No space constraints or color figure charges

- Immediate publication on acceptance

- Inclusion in PubMed, CAS, Scopus and Google Scholar

- Research which is freely available for redistribution

Submit your manuscript at www.biomedcentral.com/submit
Biomed Central 